Paidéia, 2006, 16(34), 205-212

\title{
USO DE ESTRATÉGIAS DE LEITURA POR ALUNOS DO ENSINO MÉDIO ${ }^{1}$
}

\author{
Maria Cristina Rodrigues Azevedo Joly ${ }^{2}$ \\ Lílian Mendes dos Santos \\ Janete Aparecida da Silva Marini \\ Universidade São Francisco
}

\begin{abstract}
Resumo: O presente estudo verificou o uso de estratégias metacognitivas de leitura por alunos do ensino médio. Participaram 487 alunos do ensino médio de escolas públicas, $55,7 \%$, e particulares ,44,3\%, sendo 58,3\% do sexo feminino. A idade variou de 14 a 21 anos com média de 16,2 anos e desvio padrão de 1,27. O procedimento utilizado foi a aplicação coletiva por classe de uma escala de estratégias metacognitivas de leitura. Os resultados revelaram que as mais utilizadas pelos participantes foram as de solução de problemas, especialmente durante a leitura. Os participantes do sexo feminino $(M=46,10 ; D P=12,42)$ demonstraram utilizar estratégias de leitura mais freqüentemente que os do masculino $(M=39,13 ; D P=13,94)$. Houve diferenças estatisticamente significativas quanto ao uso de estratégias metacognitivas de leitura entre 15 e 17 anos $[\mathrm{F}(7,480)=2,33 ; p<0,02]$. Verificou-se diferença de uso também entre a primeira série do ensino médio em relação a terceira e habilitação ao magistério $[\mathrm{F}(3,484)=12,36 ; p<0,00]$.
\end{abstract}

Palavras-chave: avaliação; metacognição; escala.

\section{THE STUDENT USE OF READING STRATEGIES IN HIGH SCHOOLS}

Abstract: This study aimed to verify the use of metacognitive reading strategies by high school students. The subjects, which 58.3\% were female, were 487 high school students from public (55.7\%) and private (44.3\%) schools. The age was between 14 and 16 years old, with an average of 16.2 years and standard deviation of 1.27. The procedure consisted of the colective application of metacognitive reading strategies. The results showed that the most frequent strategies used by the subjects were the problem solution ones, especially during the reading. The females subjects $(M=46.10 ; D P=12.42)$ used reading strategies more often than males $(M=39.13 ; D P$ $=13.94)$. There were significative statistical differences between subjects of 15 and 17 years when it came to the use of the metacoginitive strategies $[\mathrm{F}(7.48)=2.33 ; p<0.02]$ while reading. The use of the strategies by the first high school level was really diferent to the third and teacher preparation level $[\mathrm{F}(3.484)=12.36 ; p<0.00]$.

Key words: assessment; metacognition; scale.

\section{Estratégias de leitura}

As estratégias de leitura são habilidades usadas para promover a compreensão em situações de leitura, caracterizando-se por serem planos flexíveis que os leitores usam, adaptados às diferentes situações, variando de acordo com o texto a ser lido e o plano ou abordagem elaborada previamente pelo leitor (Duffy \& cols., 1987; Pellegrini, 1996; Serra \& Oller, 2003; Vicentelli, 2000). O termo "estratégia" é usado deliberadamente para se referir à ação de domí-

\footnotetext{
${ }^{1}$ Recebido em 13/12/05 e aceito para publicação em 01/09/06. ${ }^{2}$ Endereço para correspondência: Maria Cristina Rodrigues Azevedo Joly, Rua Alexandre Rodrigues Barbosa, 45, CEP: 13251-900, Itatiba-SP, E-mail: cristina.joly@saofrancisco.edu.br
}

nio e escolha dos leitores no alcance de metas ou objetivos desejados e, portanto, é considerada tanto uma habilidade cognitiva quanto metacognitiva (Bolívar, 2002; Kopke, 2002; Paris, Lipson \& Wixson, 1983).

As estratégias cognitivas de leitura são formas deliberadas de decodificação dos símbolos lingüísticos e construção de significado que são utilizadas visando a compreensão Kletzien (1991). Referem-se também a comportamentos e pensamentos que influenciam o processo de leitura de forma que a informação possa ser armazenada mais eficientemente (Kopke, 1997).

As estratégias metacognitivas quando aplicadas ao processo de compreensão em leitura, podem 
ser definidas como a consciência que o leitor tem sobre o próprio nível de compreensão durante a leitura e a habilidade para controlar as ações cognitivas, por meio de estratégias que facilitem a compreensão de um determinado tipo de texto ou de tarefa determinada. Essas estratégias permitem ao leitor planejar, monitorar e regular o seu próprio pensamento enquanto lê. Isto ocorre porque a meta-cognição pode ser entendida como o conhecimento e controle que a pessoa tem sobre sua própria cognição. Implica em ter conhecimento de como pensa (processos e eventos cognitivos) e do conteúdo dos mesmos (estruturas) aliado à habilidade para controlar tais processos, com o objetivo de organizá-los, revisá-los e modificá-los em função dos resultados obtidos pela aprendizagem (Bolívar, 2002).

Segundo Schraw (1998), as estratégias metacognitivas de leitura podem ser classificadas em global, suporte à leitura e solução de problemas. As globais são utilizadas para uma análise geral do texto, as de suporte à leitura envolvem o uso de materiais de referência, anotações, dentre outras ações e as de solução de problemas são usadas quando surgem dificuldades de compreensão para o leitor frente às informações apresentadas no texto.

É relevante que os alunos, de qualquer nível de ensino, saibam como utilizar as estratégias metacognitivas de leitura de modo a facilitar a sua compreensão (Carrel, Gajdusek \& Wise, 1998). Três momentos são identificados para utilização de estratégias de leitura. Antes da leitura quando se faz uma análise global do texto e predições, incluindo título, tópicos e figuras. Durante a leitura, ao se selecionar e relacionar as informações relevantes entre si e com conhecimento prévio do leitor. Depois, quando se revê reflete sobre o significado da mensagem do texto (Duke \& Pearson, 2002; Kopke, 1997).

\section{Estudos sobre estratégias de leitura}

Com a intenção de investigar o uso de estratégias cognitivas para a compreensão de textos, Mokhtari e Reichard (2002) realizaram um estudo de validação de um instrumento de auto-relato, intitulado Inventário de Consciência Metacognitiva das Estratégias de Leitura (MARSI). O instrumento avaliou a consciência metacognitiva que adolescentes e adultos têm sobre as estratégias de leitura utilizadas quando lêem material acadêmico, possibilitando-lhes verificar o quanto conseguem controlar suas metas de leitura e melhorar a compreensão do texto.Os resultados apontaram que leitores hábeis fazem, mais freqüentemente, uma análise geral do texto e frente a dificuldades de compreensão das informações usam estratégias que possam auxiliar o entendimento da informação. A relação observada entre a habilidade em leitura e o tipo de estratégia utilizada foi considerada pelos autores como evidência de validade do instrumento, pois é capaz de discriminar o desempenho em leitura em função do tipo de estratégia metacognitiva.

Tendo como finalidade avaliar o efeito de um programa de ensino de estratégias de leitura sobre o desempenho de alunos considerados maus leitores que cursavam a faculdade nos Estados Unidos, Falk-Ross (2002) conduziu um estudo com um grupo de alunos, com idade variando entre 18 e 22 anos, que passaram por pré-teste, treino e pós-teste. Os resultados indicaram diferenças estatisticamente significativas entre os resultados em compreensão destes alunos, quando comparado seu desempenho na avaliação pré e pós-programa. Verificou-se que o uso de estratégias específicas para antes da leitura (seu objetivo e organização textual), durante a leitura (revisando e clarificando as informações) e depois da leitura (resumindo e aplicando informações em atividades), possibilitou aos alunos uma integração entre as habilidades anteriormente aprendidas para ler e as informações adquiridas pela leitura.

No Brasil, Dias, Morais e Oliveira (1995) verificaram a eficácia do treinamento no uso de estratégias de leitura metacognitivas entre crianças de escolas públicas e particulares de Pernambuco. Solicitaram que a criança representasse o conteúdo de cada sentença lida para ela pelo aplicador. Analisaram a relação entre o nível de compreensão da leitura oral (muita, média e pouca dificuldade) pela criança e o grau de benefício proporcionado pelo uso da representação mental como estratégia. Os resultados apontaram que as crianças, tanto de escolas públicas como das particulares, melhoraram significativamente a compreensão oral com o uso da imagem mental. O mesmo não ocorreu com as crianças do grupo controle.

Em pesquisa realizada por Boruchovitch (2001), foram investigadas estratégias de compreensão de 
conteúdo durante a leitura para situações de aprendizagem em sala de aula, estudo, realização de tarefas escolares e preparação para as provas em casa, as quais foram mencionadas espontaneamente por 110 alunos do Ensino Fundamental. Os participantes foram entrevistados individualmente e solicitados a relatar como compreendiam as informações lidas nas diferentes situações de aprendizagem investigadas. Os resultados revelaram que a maioria dos participantes buscou apoio social $(44,3 \%)$ como estratégia para tentar compreender a leitura quando tinha dificuldade. Reler foi mencionado por $31,8 \%$ como uma alternativa para solucionar o problema de compreensão. Uma minoria $(11,4 \%)$ reportou que, primeiramente, tentava resolver a dificuldade sozinha, por meio da releitura, e quando não conseguia buscava também o apoio social. O uso de objetos de apoio, como por exemplo, o dicionário, foi uma categoria de resposta pouco freqüente $(4,5 \%)$. Relações significativas entre as estratégias de leitura usadas e a repetência foram encontradas. Os alunos repetentes usaram menos estratégias frente a dificuldades de compreensão do que os não repetentes. Não se identificaram diferenças estatisticamente significante entre estratégias de compreensão e idade, gênero e série escolar dos participantes. Constatou-se a necessidade de que professores e educadores atentem para a importância de se desenvolver um trabalho preventivo para a formação do leitor independente, crítico e reflexivo.

Dias e Calsa (2003) verificaram as estratégias de compreensão textual utilizadas por alunos de quatro séries alternadas $\left(2^{\mathrm{a}}, 4^{\mathrm{a}}, 6^{\mathrm{a}}\right.$ e $8^{\mathrm{a}}$ séries) do Ensino Fundamental de uma escola pública do Paraná. Os alunos foram avaliados por meio da leitura de textos literários e informativos. Era solicitado que lessem os textos, os recontassem espontaneamente e verbalizassem os procedimentos utilizados para compreendê-los em entrevistas individuais. Os resultados revelaram uma correspondência entre desempenho na tarefa de compreensão textual e a verbalização dos processos utilizados durante a compreensão. Verificou-se que com esse procedimento os alunos compreenderam melhor o texto literário do que o informativo.

Joly (2005), constatando a inexistência de instrumentos para avaliar estratégias metacognitivas de leitura disponíveis na literatura científica brasileira pertinente, construiu uma escala para estudantes do ensino médio baseada em instrumentos acadêmicos americanos de avaliação. Além destes, considerouse o estudo de validação da escala desenvolvida por Mokhtari e Reichard (2002) e de Joly, Cantalice e Vendramini (2004) para alunos universitários.

O estudo exploratório da primeira versão da escala que contava com 67 itens do tipo Likert com três opções de freqüência (nunca, algumas vezes e sempre) foi realizado com 490 alunos, sendo 58,6\% do sexo feminino e $41,4 \%$ do masculino, que freqüentavam o ensino médio em escolas públicas $(55,7 \%)$ e privadas $(44,3 \%)$ em cidades do interior paulista. A idade variou de 14 a 21 anos $(M=16,20 ; D P=1,28)$. A análise fatorial para extração de fatores com rotação Promax e normalização Kaiser da amostra de 0,92 , determinaram a presença de três fatores (estratégias metacognitivas globais, suporte e solução de problemas) que explicam $39,43 \%$ da variabilidade dos 39 itens da escala que apresentaram carga fatorial entre 0,40 e 0,81 . Identificou-se também que os fatores acham-se correlacionados entre si. A correlação de Pearson entre global e suporte foi de 0,50, entre global e solução de problemas de 0,53 e de suporte e solução de problemas de 0,47 . Em relação à fidedignidade do instrumento final, o coeficiente Alfa de Crombach indicou uma precisão alta do instrumento $(a ́=0,92)$. Os itens excluídos contribuíram para o aumento da precisão do instrumento como um todo. Para as estratégias metacognitivas globais (á $=$ $0,85)$, suporte à leitura $(a ́=0,84)$ e solução de problemas (á =0,85), os coeficientes Alfa de Crombach aferidos indicaram também uma precisão alta. Estes resultados conferiram validade de construto à escala, por suas características psicométricas constatadas.

Diante das pesquisas citadas, observa-se que o uso de estratégias de leitura nos diferentes níveis escolares está relacionado à efetiva compreensão da leitura (Carrell, Gajdusek \& Wise, 1998) e considerando-se que o Ensino Médio é uma etapa da vida escolar onde os alunos buscam aperfeiçoar suas habilidades visando o ingresso na universidade, a leitura torna-se ainda mais importante (Solé, 1998). Desta forma, é pertinente verificar quais são as estratégias utilizadas pelo estudante de Ensino Médio e sua freqüência de uso. Esses são, pois, os objetivos do pre- 
sente estudo, bem como identificar as possíveis diferenças em relação ao gênero, idade, série e tipo de escola freqüentada.

\section{Método}

\section{Participantes}

A pesquisa contou com 487 participantes, estudantes do Ensino Médio, sendo 284 do gênero feminino $(58,3 \%)$ e 203 do gênero masculino( $41,7 \%)$. As idades variaram entre 14 e 21 anos, tendo como média, 16,2 anos e desvio padrão 1,27. Participaram da pesquisa instituições educacionais da rede pública $(55,7 \%)$ e particular $(44,3 \%)$ de ensino. Com relação às séries, 218 alunos $(44,7 \%)$ pertenciam ao $1^{\circ}$ ano do Ensino Médio, 98 alunos (20,1\%) ao $2^{\circ}$ ano, 88 alunos (18\%) ao $3^{\circ}$ ano e 83 alunos (17\%) cursavam o $4^{\circ}$ ano de habilitação ao magistério.

\section{Instrumento}

Escala de Estratégias Metacognitivas de Leitura - formato Ensino Médio (EMeL - EM) (Joly, 2005). Anexo 1

Tem por objetivo avaliar o tipo e a freqüência de estratégias de leitura que os jovens estudantes utilizam antes, durante e depois da leitura de textos informativos. É composta por 39 afirmações do tipo Likert com três opções de freqüência - nunca, algumas vezes e sempre - divididas em três fatores. São 14 estratégias metacognitivas globais (questões 1,2 , $3,4,5,6,18,19,21,22,24,26,29,36), 10$ estratégias metacognitivas de suporte à leitura (questões 12, 13, $16,27,32,33,34,37,38,39)$ e 15 estratégias metacognitivas de solução de problemas (questões 7 , 8, 9, 10, 11, 14, 15, 17, 20, 23, 25, 28, 30, 31, 35). Esses fatores explicam $39,43 \%$ da variabilidade da escala. A precisão total da escala é de á $=0,92$ e de á $=0,85$ para estratégias metacognitivas globais e de solução de problemas e á $=0,84$ para as de suporte à leitura. As características psicométricas da escala conferem-lhe a possibilidade de uso para o objetivo a que se propõe.

\section{Procedimento}

$\mathrm{O}$ instrumento foi respondido pelos participantes que tiveram o Termo de Consentimento Livre e Esclarecido da Pesquisa autorizado pelos responsáveis, quando menor de 18 anos, ou assinados por eles próprios, se maiores de idade. A aplicação foi coletiva por classe, em sessão única. Os participantes foram orientados a responder o instrumento de acordo com suas instruções. O tempo de aplicação foi, em média, de 30 minutos.

\section{Resultados e Discussão}

A pontuação média dos sujeitos nos diferentes itens da escala de estratégias de leitura foi de 43,18, com desvio padrão de 13,50. As estratégias que apresentaram maior pontuação média foram o item 8 Reler trechos quando encontro uma informação que tenho dificuldade de entendimento $(M=1,62$; $D P=0,618$ ), item 21 - Ler com atenção e devagar para ter a certeza que estou entendendo o texto $(M=1,56 ; D P=0,719)$, item 23 - Concentrar-me na leitura quando o texto é dificil $(M=1,58 ; D P=0,632)$ e item 35 - Verificar se atingi o objetivo que havia estabelecido para a leitura $(M=1,07$; $D P=0,712)$. Esta verificação indica que os alunos tendem a usar mais freqüentemente as estratégias metacognitivas de solução de problemas (itens 8, 23 e 35). Esses resultados corroboram o estudo de FalkRoss (2002) e Mokhtari e Reichard (2002) os quais verificaram que frente às dificuldades de compreensão das informações, os estudantes fazem uso de ações que os auxiliam na compreensão do texto.

$\mathrm{O}$ momento que apresentou itens com menor pontuação média foi após a leitura. O item 33 -Fazer lista dos tópicos mais importantes do texto $(M=0,70 ; D P=0,698)$ e o item 38-Copiar os trechos mais importantes do texto $(M=0,73 ; D P=0,714)$ são os de menor escore. Estes referem - se à estratégia metacognitiva de suporte à leitura, indicando que os alunos, em sua maioria, não utilizam materiais de referências para melhor compreensão do texto, frente a dificuldades por eles identificadas após a leitura. Isto porque, provavelmente, recorrem à estratégia de solução de problemas durante a leitura e apenas frente à dificuldade.

$\mathrm{O}$ fato das estratégias metacognitivas de suporte à leitura aparecerem como as menos utilizadas podem sugerir, como em estudos de Boruchovitch (2001), Cantalice (2004) e Witter (1997) que, desde as séries iniciais, além do processo formal de alfabetização é necessário que seja ensinado aos alunos a importância da metacognição na formação de leitores hábeis. 
Tabela 1-Distribuição da freqüência percentual de respostas dos sujeitos na escala antes da leitura.

\begin{tabular}{|c|c|c|c|c|c|c|c|c|}
\hline \multirow{2}{*}{$\begin{array}{c}\text { itens } \\
\text { ANTES DALEITURA }\end{array}$} & \multicolumn{8}{|c|}{ frequência de resposta } \\
\hline & média & $\begin{array}{l}\text { desvio } \\
\text { padrão }\end{array}$ & Nunca & $\%$ & $\begin{array}{c}\text { algumas } \\
\text { vezes }\end{array}$ & $\%$ & Sempre & $\%$ \\
\hline 1 Fazer perguntas sobre o conteúdo do texto. & 0,94 & 0,686 & 130 & 26,6 & 258 & 52,7 & 102 & 20,8 \\
\hline 2 Ver como é a organização do texto. & 1,05 & 0,719 & 115 & 23,5 & 236 & 48,2 & 139 & 28,4 \\
\hline 3 Organizar um roteiro para ler. & 0,74 & 0,707 & 203 & 41,4 & 212 & 43,3 & 75 & 15,3 \\
\hline 4 Levantar hipóteses sobre o conteúdo do texto. & 1,01 & 0,696 & 116 & 23,7 & 253 & 51,6 & 121 & 24,7 \\
\hline
\end{tabular}

Considerando o momento da leitura (Tabela 1), a pontuação média antes da leitura foi de 0,93 e os itens que possuem maior freqüência são: o item 2 - Ver como é a organização do texto $(M=1,05$; $D P=0,719)$ e item 4 - Levantar hipóteses sobre o conteúdo do texto $(M=1,01 ; D P=0,696)$. Esse re- sultado pode revelar uma leitura baseada em planejamento e organização de ações que visem um melhor nível de compreensão, pela análise global do texto e o uso do conhecimento prévio na préleitura (Pelegrini, 1996; Duke \& Pearson, 2002; Kopke, 1997).

Tabela 2 - Distribuição da freqüência percentual de respostas dos sujeitos durante a leitura

\begin{tabular}{|c|c|c|c|c|c|c|c|c|}
\hline \multirow{2}{*}{$\begin{array}{c}\text { itens } \\
\text { DURANTE A LEITURA }\end{array}$} & \multicolumn{8}{|c|}{ frequência de resposta } \\
\hline & média & $\begin{array}{l}\text { desvio } \\
\text { padrão }\end{array}$ & Nunca & $\%$ & $\begin{array}{l}\text { algumas } \\
\text { vezes }\end{array}$ & $\%$ & Sempre & $\%$ \\
\hline 1 Fazer comentánios críticos sobre o texto. & 1,12 & 0,673 & 84 & 17,1 & 261 & 53,3 & 145 & 29,6 \\
\hline 2 Opinar sobre as informações do texto. & 1,21 & 0,671 & 69 & 14,1 & 248 & 50,6 & 173 & 35,3 \\
\hline 3 Parar de ler para ver se estou entendendo. & 1,4 & 0,685 & 56 & 11,4 & 184 & 37,6 & 250 & 51 \\
\hline $\begin{array}{l}4 \text { Reler trechos quando encontro uma informação que terho dificuldade de } \\
\text { entendimento. }\end{array}$ & 1,62 & 0,618 & 36 & 7,3 & 112 & 22,9 & 342 & 69,8 \\
\hline 5 Reler em voz alta os trechos que näo compreendi. & 1,28 & 0,769 & 95 & 19,4 & 162 & 33,1 & 233 & 47,6 \\
\hline 6 Voltar a ler alguns parágrafos ou páginas já lidas quando me distraio. & 1,34 & 0,743 & 80 & 16,3 & 164 & 33,5 & 246 & 50,2 \\
\hline $\begin{array}{l}7 \text { Verificar se as hipóteses que fiz sobre o conteúdo do texto estão certas } \\
\text { ou erradas. }\end{array}$ & 0,99 & 0,703 & 124 & 25,3 & 248 & 50,6 & 118 & 24,1 \\
\hline 8 Grifar o texto para destacar as informações que acho importante. & 1,02 & 0,773 & 142 & 29 & 198 & 40,4 & 150 & 30,6 \\
\hline 9 Fazer anotações ao lado do texto. & 0,93 & 0,794 & 173 & 35,3 & 179 & 36,5 & 138 & 28,2 \\
\hline 10 Consultar o dicionánio para entender o significado de palavras novas. & 1,04 & 0,731 & 121 & 24,7 & 228 & 46,5 & 141 & 28,8 \\
\hline 11 Fixar a atenção em determinados trechos do texto. & 1,33 & 0,601 & 34 & 6,9 & 259 & 52,9 & 197 & 40,2 \\
\hline 12 Fazer anotaçöes sobre os pontos mais importantes do texto. & 1,05 & 0,757 & 129 & 26,3 & 209 & 42,7 & 152 & 31 \\
\hline $\begin{array}{l}13 \text { Ler novamente trechos do texto quando rão entendo a relação entre as } \\
\text { informações. }\end{array}$ & 1,41 & 0,66 & 47 & 9,6 & 194 & 39,6 & 249 & 50,8 \\
\hline 14 Relacionar o assunto do texto com o que já conheço sobre o assunto. & 1,21 & 0,805 & 72 & 14,7 & 250 & 51 & 167 & 34,1 \\
\hline 15 Deduzir informaçöes do texto que leio para compreendê-lo. & 1,2 & 0,65 & 64 & 13,1 & 264 & 53,9 & 162 & 33,1 \\
\hline 16 Analisar se as informações são lógicas e fazem sentido. & 1,26 & 0,687 & 68 & 13,9 & 226 & 46,1 & 196 & 40 \\
\hline 17 Ler com atenção e devagar para ter certeza que estou entendendo o texto. & 1,56 & 0,719 & 21 & 4,3 & 181 & 36,9 & 287 & 58,6 \\
\hline 18 Reler trechos para relacionar as informações do texto. & 1,23 & 0,667 & 65 & 13,3 & 246 & 50,2 & 179 & 36,5 \\
\hline 19 Concentrar-me na leitura quando o texto é dificil. & 1,58 & 0,632 & 38 & 7,8 & 130 & 26,5 & 322 & 65,7 \\
\hline 20 Questionar o texto para entendê-lo melhor. & 1,07 & 0,708 & 107 & 21,8 & 243 & 49,6 & 140 & 28,6 \\
\hline $\begin{array}{l}21 \text { Ficar atento aos nomes, datas, época e locais que aparecem no texto para } \\
\text { compreende-lo. }\end{array}$ & 1,26 & 0,693 & 70 & 14,3 & 222 & 45,3 & 198 & 40,4 \\
\hline $\begin{array}{l}22 \text { Fazer suposições sobre o significado de um trecho do texto quando não } \\
\text { entendo. }\end{array}$ & 1,18 & 0,648 & 66 & 13,5 & 268 & 54,7 & 156 & 31,8 \\
\hline 23 Interpretar o que o autor quis dizer. & 1,23 & 0,698 & 75 & 15,3 & 225 & 45,9 & 190 & 38,8 \\
\hline 24 Ler em voz alta quando o texto é dificil. & 1,06 & 0,812 & 148 & 30,2 & 166 & 33,9 & 176 & 35,9 \\
\hline 25 Diferenciar as informações da opinião do autor. & 0,96 & 0,678 & 124 & 25,3 & 264 & 53,9 & 102 & 20,8 \\
\hline
\end{tabular}


Durante a leitura, a pontuação média foi de 1,22 pontos (Tabela 2 ) e os itens que possuem maior pontuação média são: o item 8 -Reler trechos quando encontro uma informação que tenho dificuldade de entendimento $(M=1,62 ; D P=0,618)$, o item 17 - Ler novamente os trechos do texto quando não entendo a relação entre as informações $(M=1,41 ; D P=0,660)$, o item 21 - Ler com atenção e devagar para ter certeza que estou entendendo o texto $(M=1,56 ; D P=0,719)$ e o item 23 - Concentrar-me na leitura quando o texto é dificil $(M=1,58 ; D P=0,632)$. As estratégias relatadas como de uso mais freqüente metacognitiva de suporte à leitura nesse momento de leitura foram as metacognitivas de solução de problemas, indicando que, sua utilização é prioritariamente durante a leitura, quando o leitor se depara com a dificuldade de compreensão do texto. Este resultado corrobora a perspectiva de Serra e Oller (2003) que propõem que a capacidade de aprender com autonomia requer a aprendizagem de certas habilidades para compreender o que é lido.

Tabela 3-Distribuição da freqüência percentual de respostas dos sujeitos na escala após a leitura

\begin{tabular}{|c|c|c|c|c|c|c|c|c|c|}
\hline \multirow{2}{*}{\multicolumn{2}{|c|}{$\begin{array}{c}\text { itens } \\
A P O S S A L E I T U R A\end{array}$}} & \multicolumn{8}{|c|}{ frequência de resposta } \\
\hline & & média & $\begin{array}{l}\text { desvio } \\
\text { padrão }\end{array}$ & Nunca & $\%$ & $\begin{array}{l}\text { algumas } \\
\text { vezes }\end{array}$ & $\%$ & Sempre & $\%$ \\
\hline 1 & $\begin{array}{l}\text { Pensar sobre por que fiz algurmas suposições certas e outras erradas } \\
\text { sobre o texto. }\end{array}$ & 0,83 & 0,679 & 162 & 33,1 & 250 & 51 & 78 & 15,9 \\
\hline 2 & $\begin{array}{l}\text { Relembrar os principais pontos do texto para verificar se o } \\
\text { compreendi totalmente. }\end{array}$ & 1,28 & 0,73 & 81 & 16,5 & 191 & 39 & 218 & 44,5 \\
\hline 3 & $\begin{array}{l}\text { Escrever com minhas palavras as informações que destaquei como } \\
\text { mais importantes. }\end{array}$ & 0,95 & 0,762 & 154 & 31,4 & 205 & 41,8 & 131 & 26,7 \\
\hline 4 & Fazer lista dos tópicos mais importantes do texto. & 0,7 & 0,698 & 214 & 43,7 & 208 & 42,4 & 68 & 13,9 \\
\hline 5 & $\begin{array}{l}\text { Fazer um resumo do texto para organizar as informações mais } \\
\text { importantes. }\end{array}$ & 0,8 & 0,691 & 175 & 35,7 & 237 & 48,4 & 78 & 15,9 \\
\hline 6 & Verificar se atingi o objetivo que havia estabelecido para a leitura. & 1,07 & 0,712 & 108 & 22 & 240 & 49 & 142 & 29 \\
\hline 7 & $\begin{array}{l}\text { Identificar as dicas do texto que me permitiram fazer hipóteses } \\
\text { conretas sobre o conteúdo antes da leitura. }\end{array}$ & 0,96 & 0,651 & 115 & 23,5 & 282 & 57,6 & 93 & 19 \\
\hline 8 & $\begin{array}{l}\text { Fazer um esquema do texto para relacionar as informações } \\
\text { importantes. }\end{array}$ & 0,78 & 0,678 & 179 & 36,5 & 241 & 49,2 & 70 & 14,3 \\
\hline 9 & Copiar os trechos mais importantes do texto. & 0,73 & 0,714 & 210 & 42,9 & 204 & 41,6 & 76 & 15,5 \\
\hline 10 & Listar as informações que entendi com facilidade. & 0,79 & 0,727 & 193 & 39,4 & 209 & 42,7 & 88 & 18 \\
\hline
\end{tabular}

Após a leitura (Tabela 3), a média foi de 0,89 pontos e os itens com maior freqüência foram o item 31 - Relembrar os principais pontos do texto para verificar se o compreendi totalmente $(M=1,28$; $D P=0,730)$ e o item 35 - Verificar se atingi o objetivo que havia estabelecido para a leitura $(M=1,07$; $D P=0,712)$. As estratégias metacognitivas de solução de problemas apareceram com maior freqüência neste momento da leitura, confirmando, segundo Boruchovith (2001), que essas estratégias estão mais direcionadas à manutenção de um estado interno satisfatório que facilite a compreensão da leitura.

Observa-se neste estudo que, durante e após a leitura, estratégias metacognitivas para a solução de problemas são as mais utilizadas, frente a dificuldades de compreensão, resultado este que corrobora o estudo de Joly e Cantalice (2004) com universitári- os. Mokhtari e Reichard (2002) verificaram que leitores hábeis fazem uso freqüente de estratégia de solução de problemas para resolver dificuldades de compreensão. Acrescente-se que, segundo Vicentelli (2000), é esperado que o aluno consiga ler visando um objetivo, criando suas próprias estratégias de compreensão e adequando-as às características do texto, para que se torne um leitor independente, crítico e criativo. Nesse sentido, os participantes do presente estudo utilizaram estratégias próprias de leitores hábeis.

A análise inferencial dos resultados por meio do teste $t$ de student revelou que há uma diferença em relação à freqüência de resposta por gênero $[t(486)=5,80 ; p<0,00]$, sendo os participantes do sexo feminino $(M=46,10 ; D P=12,42)$ utilizam estratégias metacognitivas de leitura mais freqüentemente que os do sexo masculino $(M=39,13$; $D P=13,94)$. 
Quanto ao tipo de escola (pública ou particular), o estudo não mostrou diferença significativa. Cabe comentar que, como no estudo de Dias, Morais e Oliveira (1995) que verificaram a eficácia de um treinamento no uso de estratégias de leitura metacognitivas entre crianças de escolas públicas e particulares cujo resultado também indicou que todas as crianças melhoraram significativamente na compreensão de textos com o uso da nova estratégia, independente do tipo de escola freqüentada.

No que se refere à idade, a ANOVA revelou que há diferenças significativas quanto ao uso de estratégias metacognitivas de leitura entre 15 e 17 anos $[F(7,480)=2,33 ; p<0,02]$. Há diferenças também entre a primeira série, a terceira série do ensino médio e o quarto ano de habilitação ao magistério $[F(3,484)=12,36 ; p<0,00]$.

\section{Considerações finais}

Considerando que a leitura leva à consecução de novas aprendizagens, e que quanto maior a escolaridade, maior a exigência dos leitores serem independentes, é essencial identificar-se quais variáveis estão envolvidas no processo de formação de leitores hábeis. Investigar a metacognição por meio das estratégias para compreensão em leitura, atende a essa necessidade destacada.

Verificou-se no presente estudo que, tanto nas escolas públicas quanto nas particulares, uma das dificuldades dos alunos em compreensão reside no pouco uso que fazem de estratégias metacognitivas de leitura. Considerando-se que o instrumento de investigação é de auto-relato, e que, portanto, as evidências constatadas podem não corresponder aos fatos, algumas hipóteses sobre os resultados verificados são pertinentes. O desconhecimento sobre o que é estratégia, por quê, como quando e onde usá-la, conforme descrito por Carrel, Gajdusek e Wise (1998), pode ser uma das causas que levam ao pouco uso de estratégias de leitura. Ao lado disso, os próprios educadores pouco utilizam ou valorizam habilidades estratégicas metacognitivas como um recurso facilitador para a compreensão em leitura, como constatou Kopke Filho (1997; 2002) em suas pesquisas.

Quando há uma freqüência de uso relatada, as estratégias escolhidas são pouco diversificadas e, a maior freqüência observada foi durante a leitura e frente à dificuldade em compreender, o que pode ter influenciado no resultado geral. Tal fato corrobora Boruchovitch (2001) que considera a falta de repertório de estratégias de leitura e o seu desconhecimento como um dos problemas a serem enfrentados em leitura.

É importante que outras investigações sejam realizadas considerando-se, de um lado, a necessidade de caracterização das variáveis envolvidas na compreensão e, de outro, as relações que se estabelecem entre metacognição e leitura. Isto é imprescindível para intervenções pontuais e efetivas, especialmente no ensino médio, para estudantes com dificuldades de leitura.

\section{Referências}

Bolívar, C. R. (2002). Mediación de Estrategias Metacognitivas en Tareas Divergentes $\mathrm{Y}$ Transferencia Recíproca. Investigación $Y$ Postgrado, v.17, n.2, 1-20.

Boruchovitch, E. (2001). Algumas estratégias de compreensão em leitura de alunos do ensino fundamental. Psicologia Escolar e Educacional, v.5, n.1, 19-25.

Cantalice, L.M. (2004). Ensino de estratégias de leitura. Psicologia Escolar e Educacional, 8, 105-106.

Carrell, P.L., Gajdusek, L. \& Wise, T. (1998). Metacognition and EFL/ESL reading. Instructional Science, 26, 97-112.

Dias, L.V.H.A.A. \& Calsa, G. C. (2003). Estratégias de compreensão de textos literários e informativos por alunos do ensino fundamental. Teoria e Prática Educacional, 6, 329-340.

Dias, M.G.B.B.; Morais, E. P.M. \& Oliveira, M.C.N.P. (1995). Dificuldades na compreensão de textos: uma tentativa de remediação. Arquivos Brasileiros de Psicologia, v.47, n.4, 13-24.

Duffy, G.G., Roehler, L. R., Sivan, E., Rackliffe, G., Book, C., Meloth, M., Vavrus, L., Wesselman, R., Putnam, J. \& Bassiri, D. (1987). The effects of explaining the reasoning associated with using reading strategies. Reading Research Quarterly, 22, 347368. 
Duke, N. K. \& Pearson, P. D. (2002). Effetive practices for developing reading comprehension. In A. E. Farstrup \& S. J. Samuels (Eds.), What research has to say about reading instruction (pp. 205-242). Newark, DL: International Reading Association.

Falk-Ross, F. C. (2002). Toward the new literacy: changes in college students' reading comprehension strategies following reading/writing projects. Journal of Adolescent \& Adult Literacy, $45,278-288$.

Joly, M. C. R. A. (2005). Escala de Estratégias de Leitura - formato Ensino Médio (EELEM). Relatório de pesquisa. Universidade São Francisco. Itatiba, SP.

Joly, M. C. R. A. \& Cantalice, L. M. (2004). Avaliando estratégias de leitura com universitários. Em C. Machado, L. S. Almeida, M. Gonçalves \& V. Ramalho (Orgs.), Avaliação psicológica : formas e contextos. (pp.479-486). Braga: Psiquilíbrios Edições.

Joly, M. C. R. A.; Cantalice, L. M. \& Vendramini, C. M. M. (2004). Evidências de validade de uma escala de estratégia de leitura para universitários. Interação em Psicologia 8, 261-270.

Kletzien, S. B. (1991). Strategy use by good and poor comprehenders reading expository text of differing levels. Reading Research Quarterly, 26, 67-86.

Kopke Filho, H. (1997). Estratégias para desenvolver a metacognição e a compreensão de textos teóricos na Universidade. Psicologia Escolar e Educacional, v.1, n.2/3, 59-67.

Kopke Filho, H. (2002). Repertório de estratégias de compreensão da leitura e conhecimento metacognitivo de professores de língua portuguesa. Psicologia Escolar e Educacional, 6, 67-80.

Mokhtari, K. \& Reichard, C. A. (2002). Assessing students' metacognitive awareness of reading strategies. Journal of Educational Psychology. 94, 249-259.

Paris, S. G., Lipson, M. Y. \& Wixson, K. K. (1983). Becoming a strategic reader. In R. B. Ruddell, M. R. Ruddell, \& H. Singer (Eds.). Theoretical
Models and Processes of reading.(pp.788-714). Newark, DL:IRA.

Pellegrini, M. C. K. (1996). Avaliação dos niveis de compreensão e atitudes frente à leitura em universitários. Dissertação de Mestrado. Faculdade de Ciências Humanas, Universidade São Francisco, Bragança Paulista.

Serra, J. \& Oller, C. (2003). Estratégias de leitura e compreensão do texto no ensino fundamental e médio. Em A. Teberosky (Org.) Compreensão de leitura: a língua como procedimento. (pp. 3544) Porto Alegre: Artmed.

Solé, I. (1998). Estratégias de Leitura. Porto Alegre: Artmed.

Schraw, G. (1998). Promoting general metacognitive awareness. Instructional Science, 26, 113-125.

Vicentelli, H. (2000). Problemática de la lectura en estudantes universitarios. Psicologia Escolar e Educacional, 3, 195-202.

Witter, G. P. (1997). Psicologia, leitura e universidade. Campinas: Editora Alínea. 


\section{Anexo 1 - ESCALA METACOGNITIVA DE LEITURA-EMeL- EM} Maria Cristina Rodrigues Azevedo Joly

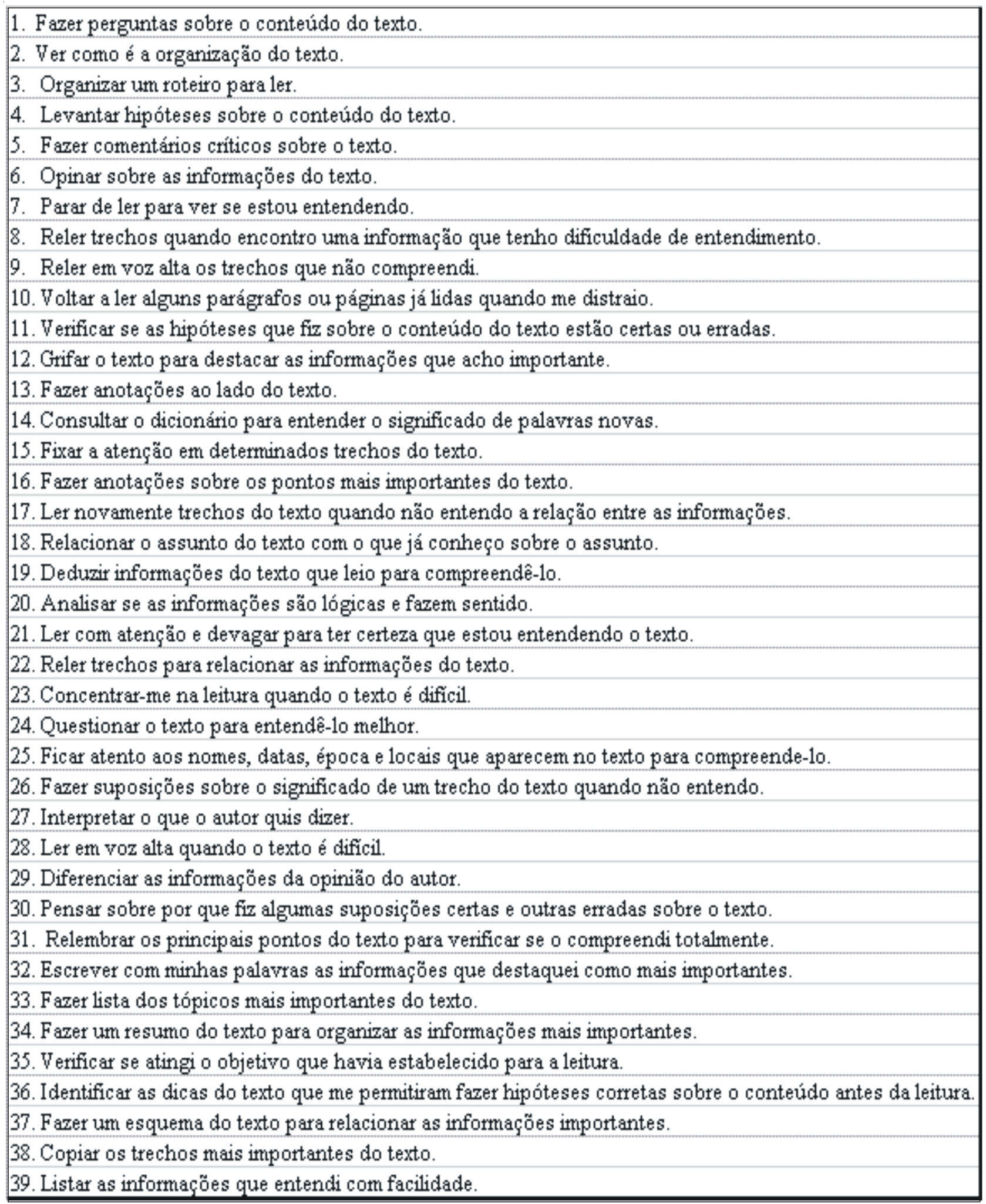

